
ac

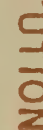

$\frac{c}{1}$
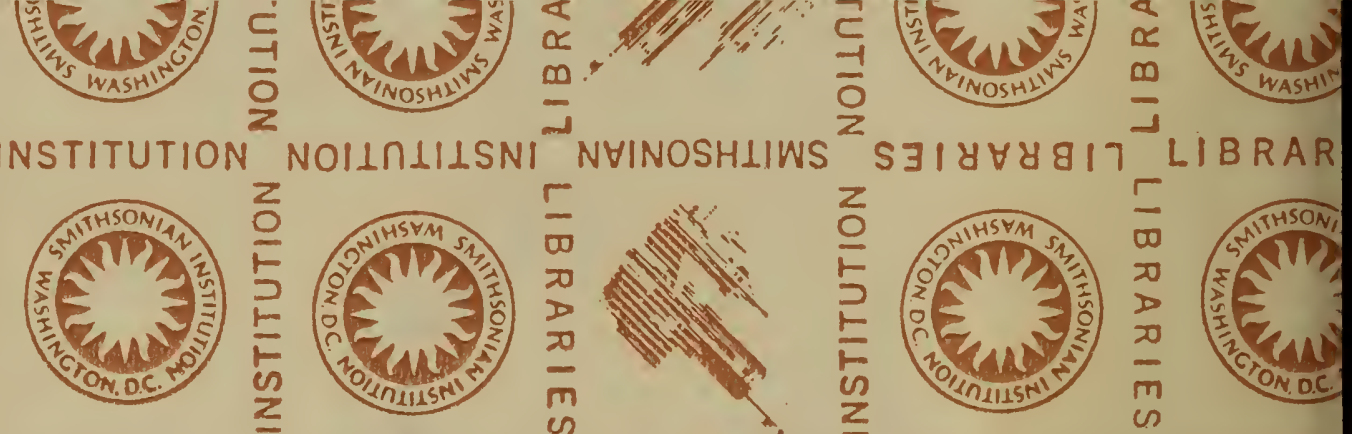

IS
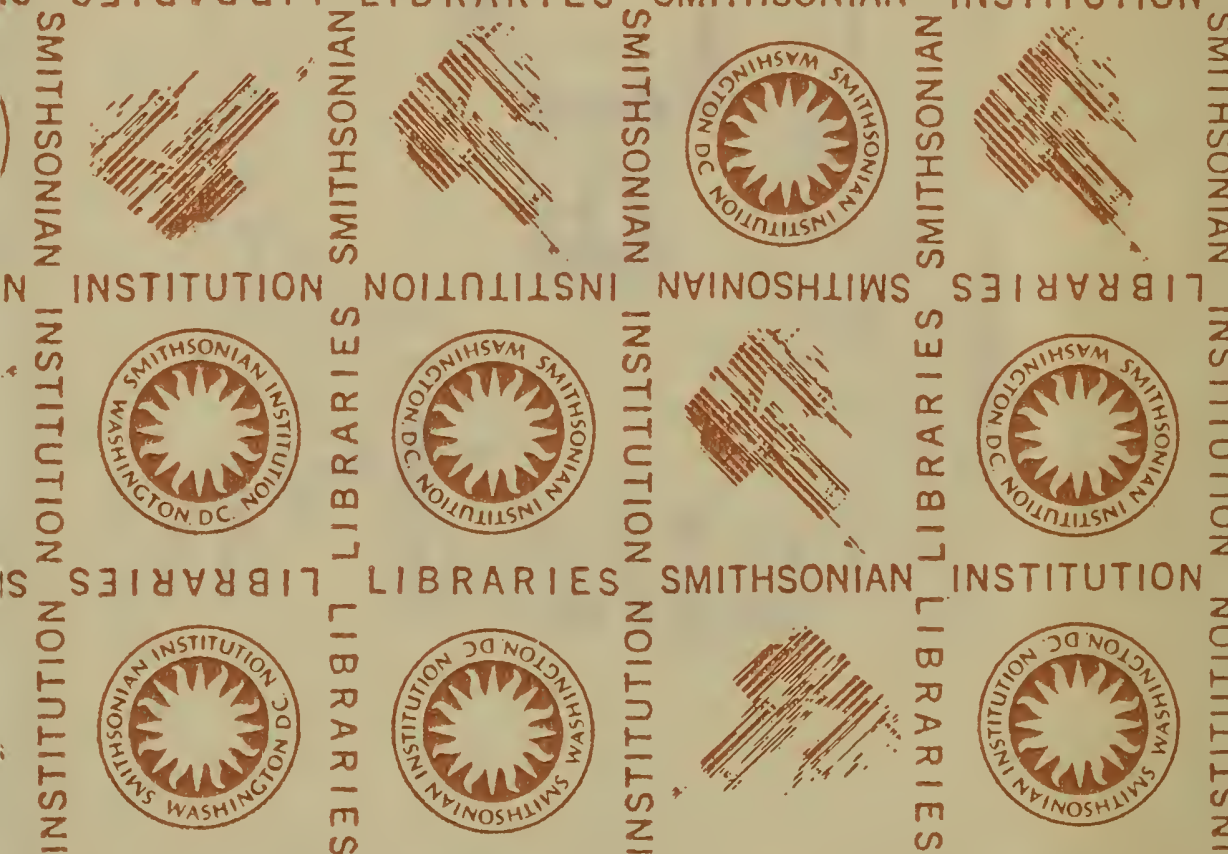

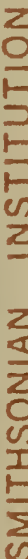
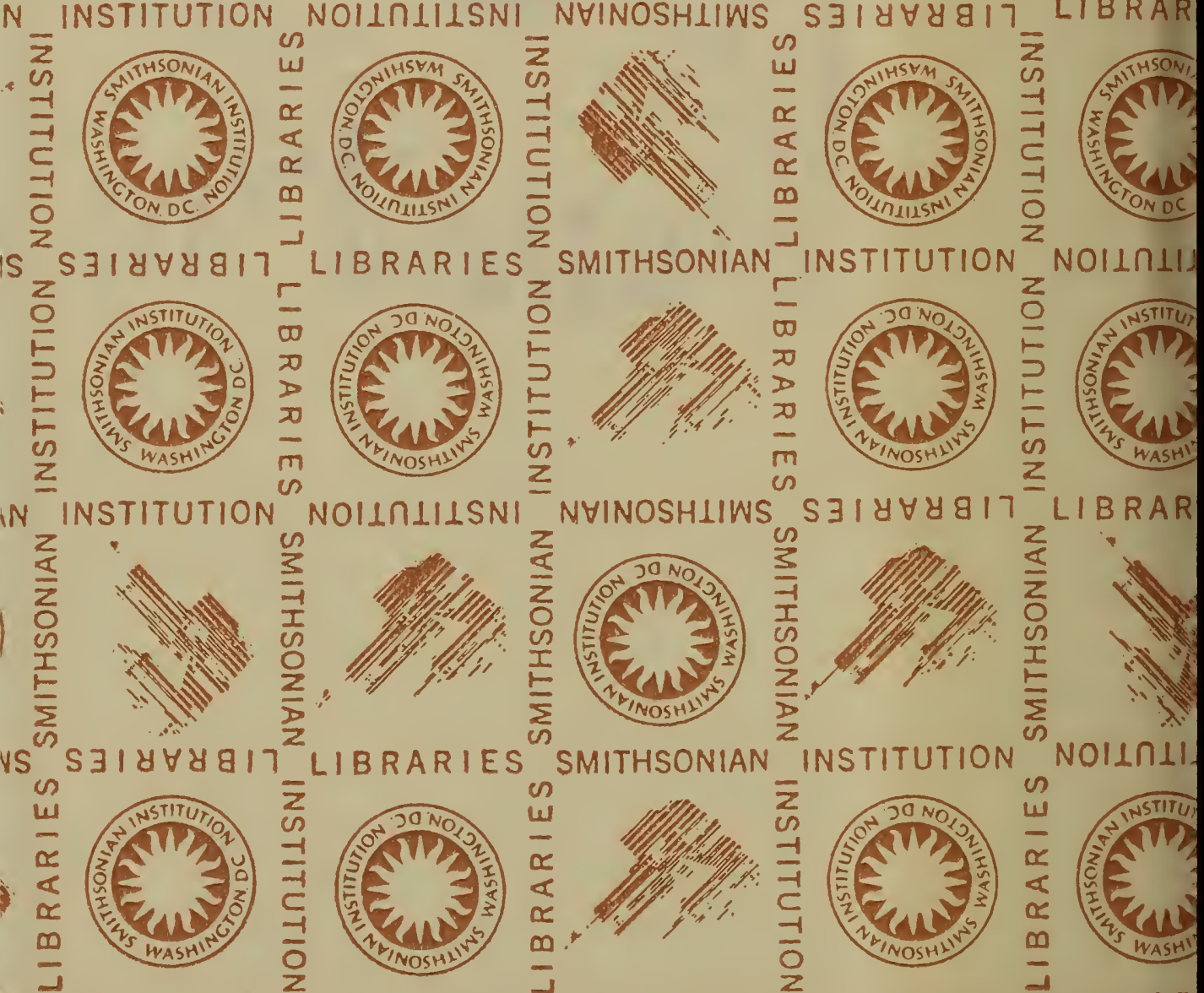

NolLnLI
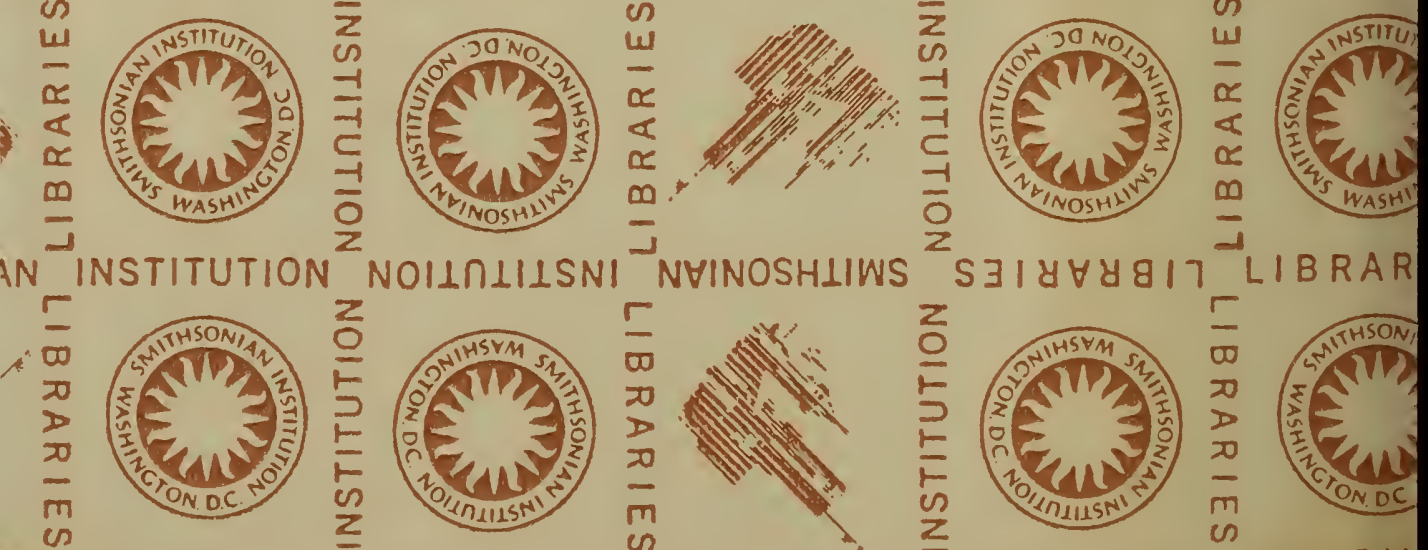

VS

$\frac{z}{s}$
LIBRAR
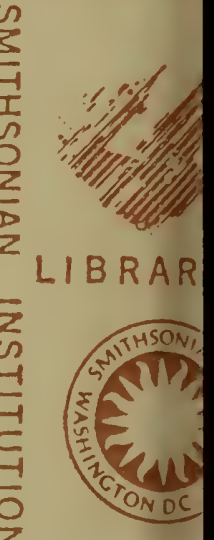



\section{LACE WORK}

A HANDBOOK

\section{ILLUSTRATED}

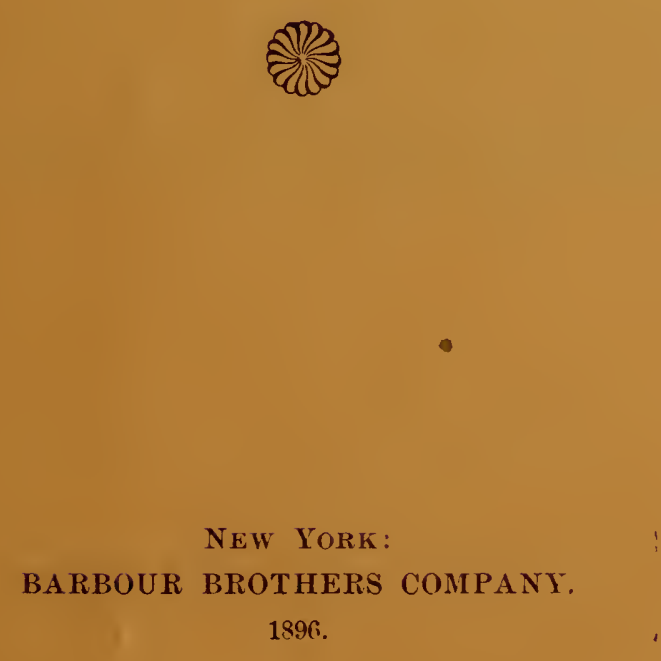


COPYRIGHT, 1896,

BY

The Barrour Brothers Company. 


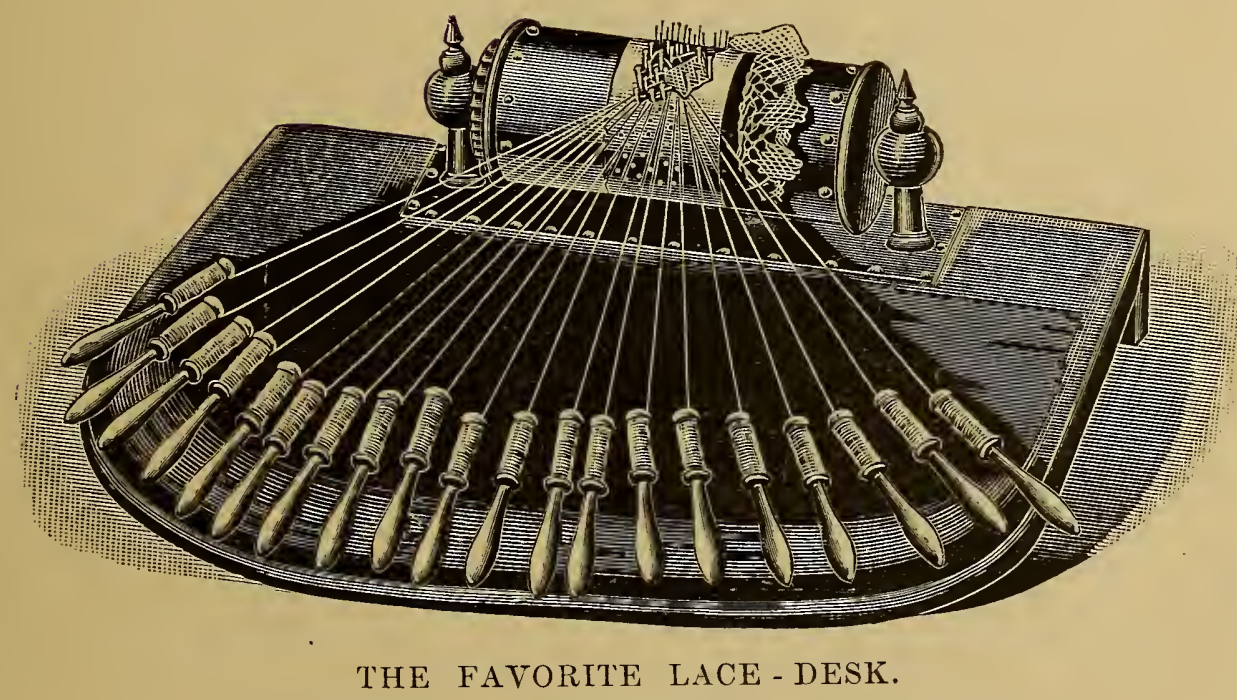




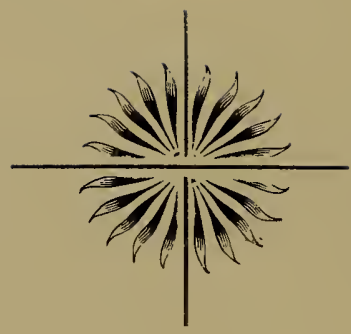




\section{Introduction.}

Torchon, or "household" lace may be called the purest and simplest of bobbin laces. It is applied to every purpose for which knitted and crocheted laces are adaptable. Being woven, it will not ravel, and its strength, durability and beauty, together with the great variety of combinations possible, render it nost desirable for general use. A mistaken notion has declared this method of lace-making difficult to learn. Instead, it is no more so than that of knitting, or crocheting, and is quite as rapidly executed. The work soon becomes mechanical, and is extremely fascinating. Although this little book is designed for beginners especially, I trust all will find something of interest and benefit in its pages. After thoroughly mastering the grounds, or "weares" and patterns presented, no one will have any difficulty in working from sample, the lace pattern being furnished. Do not say, "I cannot do this," but begin, remembering that practice soon makes perfect.

If any difficulty is experienced, the writer will gladly render all possible assistance; and, as is . the case throughout Barbour's Prize Needlework Series, all materials required will be furnished, or ladies will be directed to where they may be obtained.

Mary E. Bradford.

The Barbour Brothers Company,

Needlework Department,

218 Church Street, New York. 



\section{General Directions.}

The implements needed for work are bobbins. lace-desk, pattern and pins. A machine for winding thread on the bobbins is quite essential if one purposes to make a business of the lacemaking, but this may be had later. It should be borne in mind that only linen thread is suitable for bobbin lace, and that to insure the best results this should be smooth, lustrous, strong and flexible. It has been found by experimenting that Barbour's Irish flax threads possess these essential qualities to a much greater extent than any other on the market, and I recommend it unbesitatingly. Pins and patterns vary in size according to the No. of thread used, and purpose for which the lace is required. The same design may be used for fine and coarse lace, the pattern being enlarged or made smaller by use of the "point" or quadrille paper. No. 250, 2-cord (Barbour's lace thread), makes a delicate edging, suitable for trimming very fine handkerchiefs, etc.; the same design in No. 50, same make, and on a pattern correspondingly enlarged, produces a most useful lace for trimming underwear and similar purposes. The pins, which for ordinary torchon lace are of large size, sharp and roundheaded, are pushed in the holes designated by number. These are always put between the two pairs of bobbins last used, unless otherwise stated, and the threads "closed" around them.

To begin, wind the bobbins (from you, as you 
hold the handle in left hand), and make a loop at the end of each to prevent the thread slipping off too fast. (Fig. 1.) By turning the bobbin carefully as it lies on the desk, the thread may be unwound as needed, and this action soon becomes mechanical to the worker, as does that of drawing up and straightening the threads. It is desirable to wind each bobbin as full as convenient, in order to avoid frequent joinings. When necessary to join on a freshly-filled bobbin, lap the ends of thread for two or three inches, make a loop around the forefinger of left hand in the usual way, then bring the ends through the loop, over the threads, and draw up tight and cut off ends. This is as secure as the complicated "weaver's knot," and very simple. A little practice will enable one to tie it perfectly. Pin the pattern smoothly around the cylinder, taking care that it matches in order to be continuous. If too large, which is not often the case. wind a strip of soft cloth or felt around the roll before pinning on. Tie the bobbin threads together at the ends in pairs, pinning in holes designated as many pairs as are specitied in the directions. The bobbins are nsed and numbered by pairs, always according to the place they occupy at time of using, and beginning at the left. 'T'wo pairs-right and left -are used at a time, and the "stitches" are formed by the "twist" and "cross" of bobbin

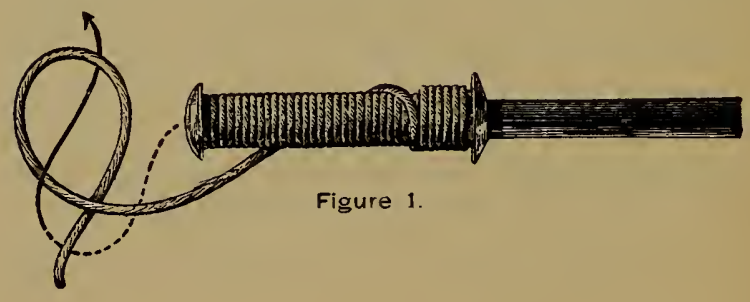


threads. The cross consists in passing the right bobbin of the left pair over the left bobbin of the right pair-or, passing the $2 d$ of the four bobbins over the $3 \mathrm{~d}$. The twist is simply carrying the right bobbin of each pair over the left of same pair, or passing the $2 d$ and 4 th over 1st and $3 \mathrm{~d}$. These are the only movements made in the laces given. Together, they form the half-throw (ht), and the whole-throw (wt) is the half-throw repeated. In the linen ground, as used in "spiders," etc., we have the half-throw and cross, or ctc-cross, twist, cross. 'This makes a close texture. Torchon laces are made up of grounds or "weaves" in a variety of combinations, and to these is devoted considerable space. 


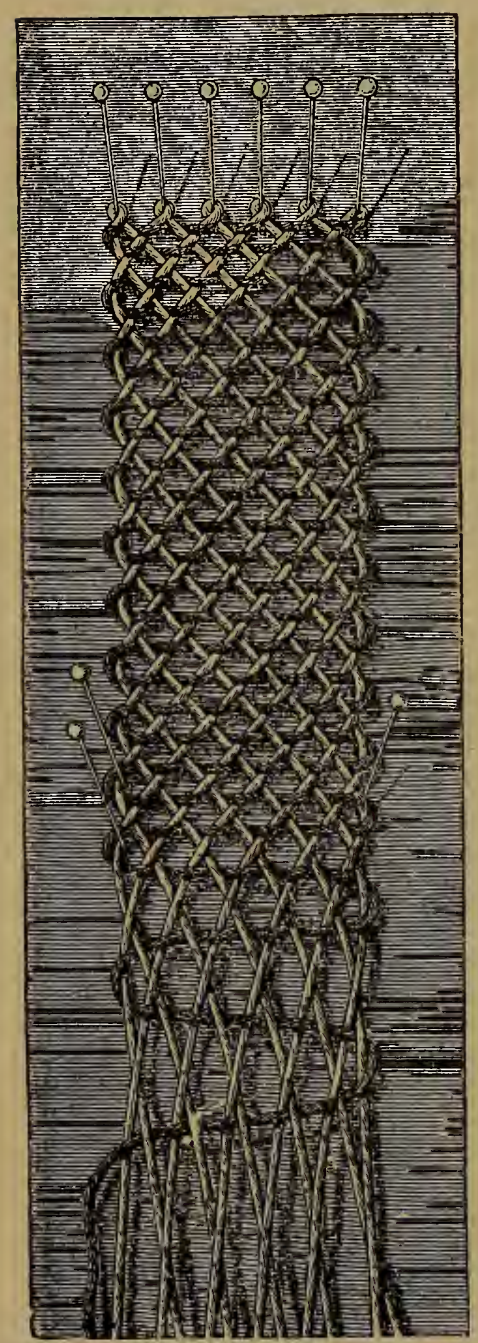

Net Ground.

\section{Net Ground.}

This is made entirely with half-throws. Pin the pattern around the cylinder, and pin 1 pair of bobbins in each of 6 holes across the pattern. Beginning at the right, ht with 5th and 6 th pairs, same with 4 th and 5th, $3 d$ and 4 th, $2 \mathrm{~d}$ and $3 \mathrm{~d}, 1$ st and $2 \mathrm{~d}$, pin in 1, close with ht. (The closing is always done, and with ht, unless otherwise directed.) Now, working to the right, lit with $2 \mathrm{~d}$ and $3 \mathrm{~d}, 3 \mathrm{~d}$ and 4th, 4th and 5th, 5th and 6 th, pin in 2, close; work left, again, to 1 st and $2 d$ pairs, putting pin in 3 , and so continue to length desired.

These grouuds form pretty insertions, and are useful in a variety of ways.

This pattern may be used for linen ground by hanging on an extra pair of bobbins at 6 th pin. 


\section{Plain Hole \\ Ground.}

Also made with halfthrows. Pin pattern around cylinder, and pin 2 pairs of bobbins in each of 5 holes across, having threads of nearly uniform length and long enough to work nicely. Ht with 2d and $3 \mathrm{~d}$ pairs, piu in 1, close; ht with 1st and $2 \mathrm{~d}$, pin in 2, close; ht with 4 th and 5th, pin in 3 , close; ht with $3 \mathrm{~d}$ and 4 th, pin in 4 , close; ht with $2 \mathrm{~d}$ and $3 \mathrm{~d}$, pin in 5 , close; ht with lst and $2 \mathrm{~d}$, pin in 6 , close; and continue to work in this way. This ground, with the "twisted hole ground,"which is worked on the same pattern, and differs only in the making of an extra twist after the halfthrow inclosing the pin, is perhaps more used in the making of torchon lace than any other.

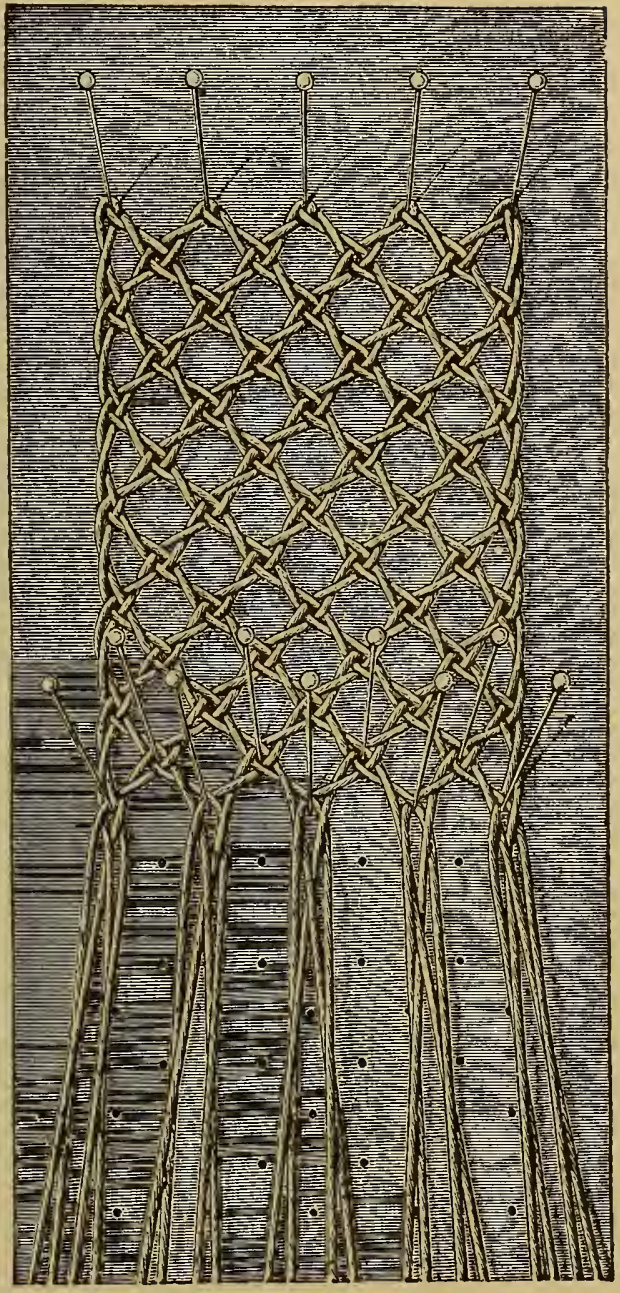

Plain Hole Ground. 


\section{Twisted Hole Ground, with} "Spider."

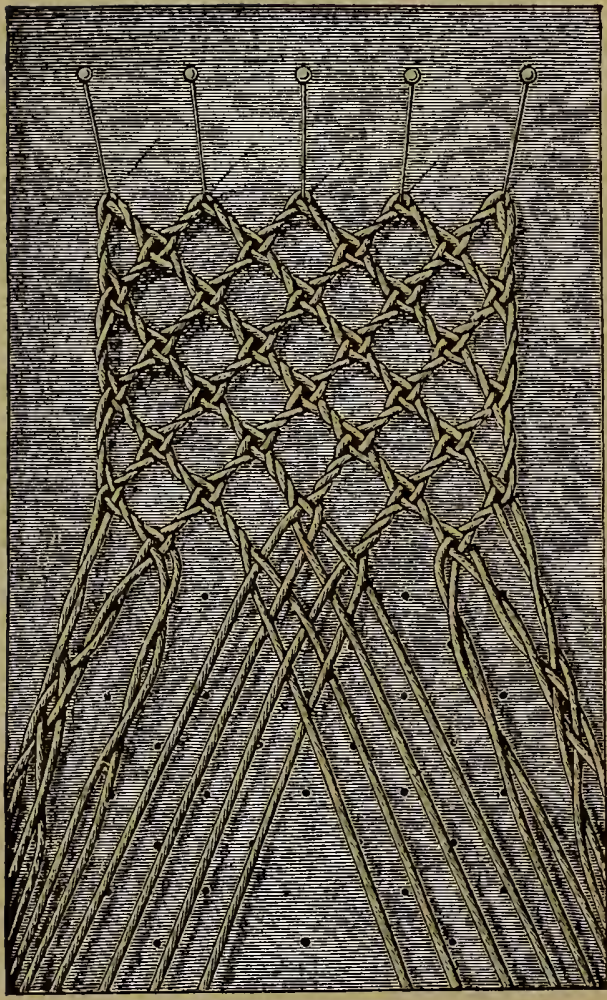

Twisted Hole Ground, with "Spider."
Work as directed for plain hole ground, making the extra twist. To form the spider, or wheel, use the 4 middle pairs4th, 5th, 6th and 7 th. Twist 5th and 6th (in plain hole ground they must be twisted twice), ctc; tw 4 th, cte with 4 th and 5th, tw 7 th, etc with 6 th and 7 th, etc with 5 th and 6 th, pin in hole between the 2 pairs, centre of spider, close with ctc, ctc with 4th and 5 th, 6 th and 7 th, 5th and 6 th, tw each pair once and proceed. It will be seen that for each pair of "legs" in the spider, a pair of bobbins is used.

As this pattern is designed mainly for practice, the "spider" is not marked. The centre pin, however, comes midway between holes 25 and 34 , and therefore these holes, with 26 and 33 , are not pinned in, as the worker readily discovers. It is a good plan to make a whole-throw, on each edge, before and after the pin, thus making the edge firmer. The holes in pattern, as will be seen, are numbered diagonally from left to right. 


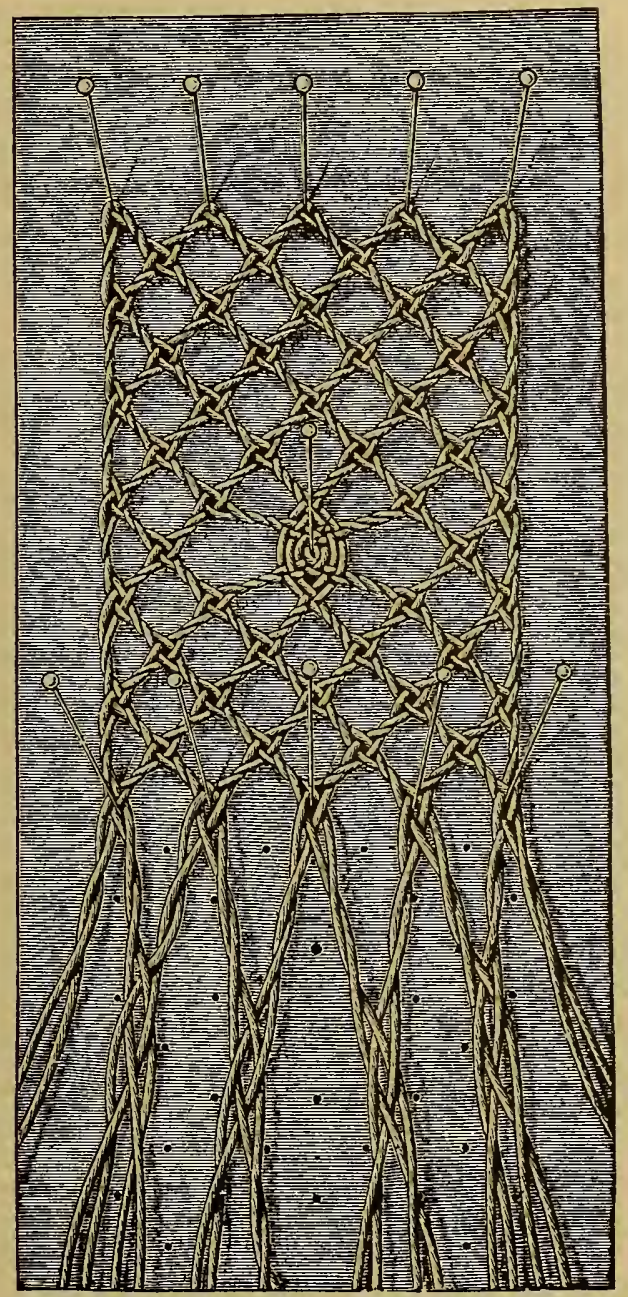

Twisted Hole Ground, with "Spider" Completed. 


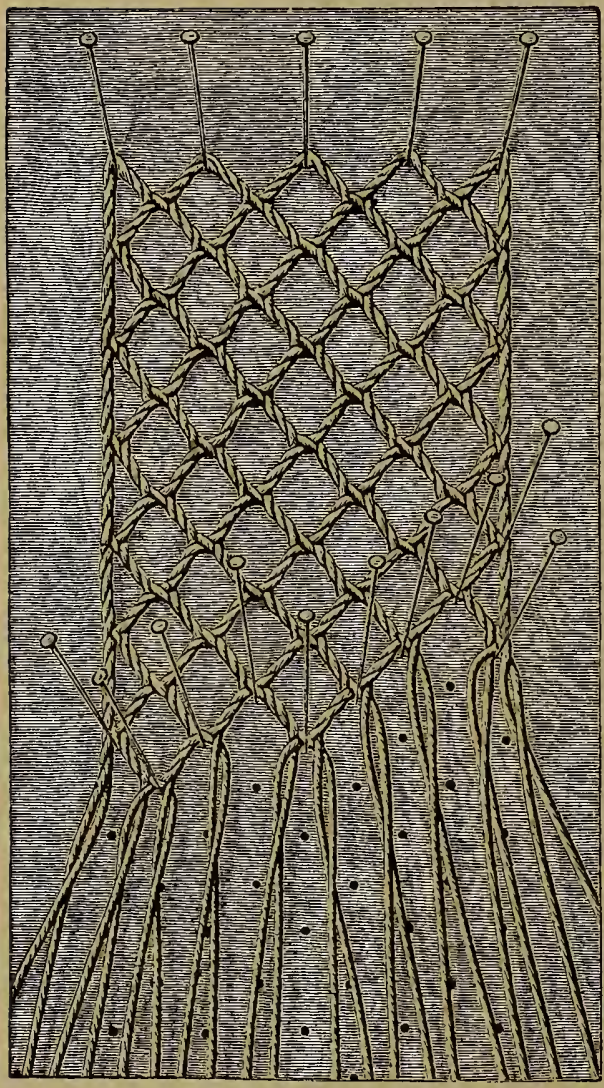

Tulle Ground.

\section{Tulle Ground.}

Pattern same as for open hole ground, and bobbins pinned on in same way. This ground is worked exactly as is the twisted hole ground, only that you do not close in any of the pins save those on the edge, for the selvage. Ht with 1st and $2 d$ pairs, pin in 1 - remembering not to close. Ht with 1st and $2 \mathrm{~d}$, pin in 2, close - this for the edge; ht $3 d$ and 4 th, pin in 3 ; ht $2 d$ and $3 \mathrm{~d}$, pin in 4 ; ht 1 st and $2 \mathrm{~d}$, pin in 5 , close. Continue in this way. The illustration is much enlarged to show the method of work. Made in fine thread, this ground is the foundation of many of the beautiful Mechlin and Brussels laces. 


\section{Brussels Ground.}

Use same pattern as for bole ground, but instead of a half-throw before and after the pin, make a whole-throw. Thus: Wt with $2 \mathrm{~d}$ and $3 \mathrm{~d}$, pin in 1 , close with wt; wt with 1 st and $2 \mathrm{~d}$, pin in 2 , wt, and continue.

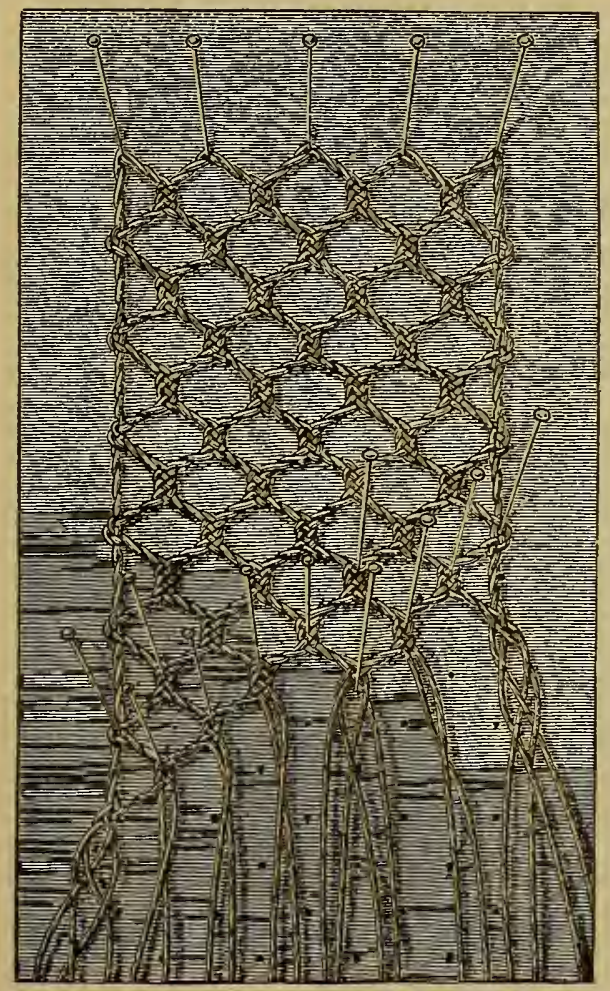

Brussels Ground. 


\section{Valenciennes Ground.}

This is formed of plaits for which 2 pairs of bobbins are used, and made with 4,6 or 8 halfthrows, according to the size of squares. The pattern consists simply of diagonal rows of holes, as for hole ground. Pin 2 pairs in 1 st hole at the left, and 4 pairs in each of remaining holes. Make

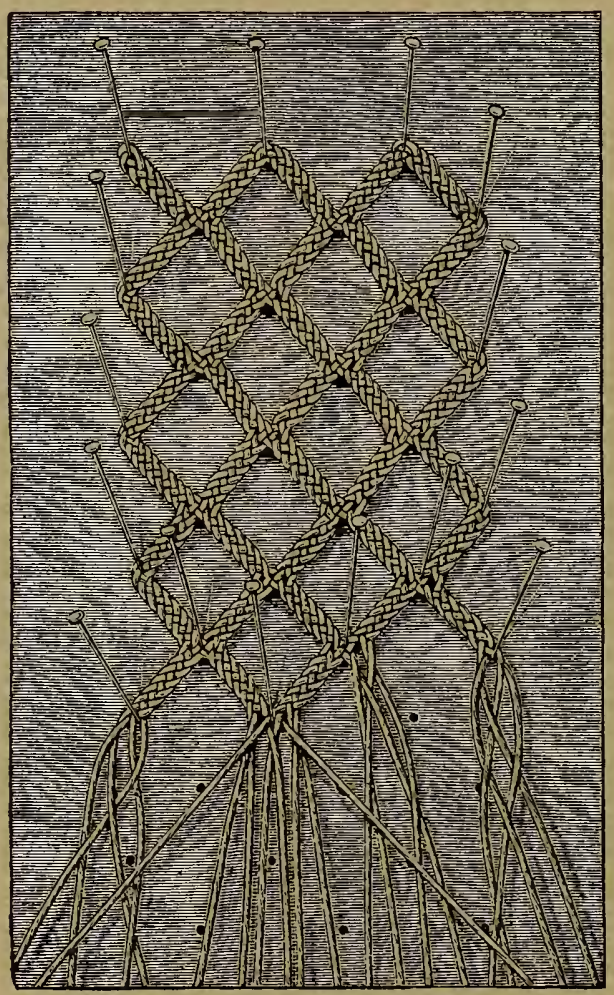

Valenciennes Ground.

6 ht $(3 \mathrm{wt})$ with 1 st and $2 \mathrm{~d}$ pairs, same with $3 \mathrm{~d}$ and 4 th; now with the 4 pairs, using a pair as 1 bobbin, make a ht, pin in 1 , cross; this makes a neat joining. Continue making the plaits and joining in same way. To cross, in this instance, pass the $2 \mathrm{~d}$ pair of bobbins over the $3 \mathrm{~d}$. Then proceed with next plait. 


\section{Pin-Check or Ornamental Ground.}

This pattern is like that for plain hole ground, save that it is differently numbered. It may be worked narrow or wider, as liked. Pin 2 pairs each in a, b, c, d, e, $\mathrm{f}$ and $\mathrm{g}$. Ht with $2 \mathrm{~d}$ and $3 \mathrm{~d}$, ht 1 st and $2 \mathrm{~d}$, pin in 1 , close (with ht); ht $3 \mathrm{~d}$ and 4 th, pin in 2, close; ht $2 \mathrm{~d}$ and $3 \mathrm{~d}$, pin in 3 , close ; ht 1 st and $2 \mathrm{~d}$, pin in 4 , close; ht $3 \mathrm{~d}$ and 4 th, 5th and 6 th, pin in 5, close; lit 7 th and 8th, pin in 6 , close; ht 6 th and $7 \mathrm{th}$, pin in 7 , close; ht 5th and 6th, 6th and 7 th, 4th and 5th, pin in 8 , close; ht $3 \mathrm{~d}$ and 4 th. pin in 9 , close; ht 5th and 6 th, pin in 10 , close; ht 4th and 5th, pin in 11, close; ht $3 \mathrm{~d}$ and 4th, 4th and 5th; ht $2 \mathrm{~d}$ and $3 \mathrm{~d}$, pin in 12 , close; ht lst and 2-d, pin in 13, close; ht $3 \mathrm{~d}$ and 4th, pin in 14, close; ht $2 d$ and $3 d$, pin in 15, close; ht 1st and $2 \mathrm{~d}$, pin in 16 , close; ht 9 th and 10th, pin in 17, close; ht 11 th and 12 th, pin in 18 , close; ht 10th and 11th, pin in 19 , close; ht 9 th and 10 th, 10th and 11th. Continue.

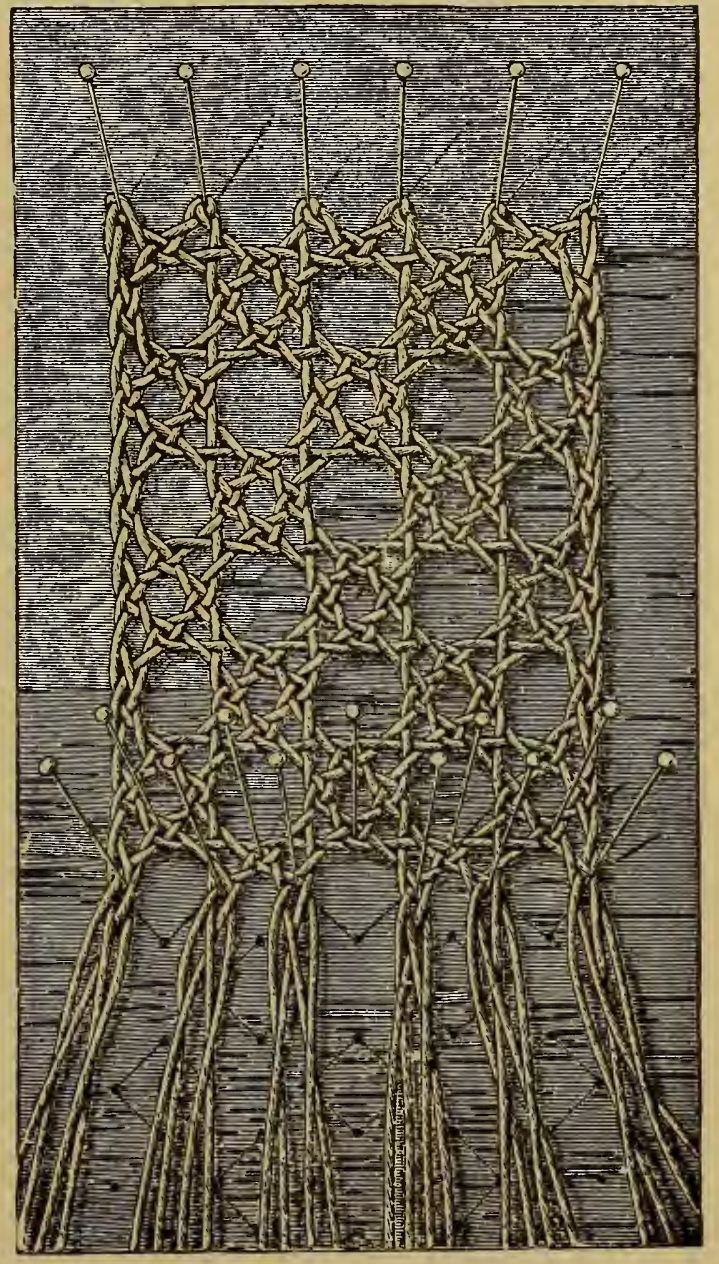

Pin-Check or Ornamental Ground. 


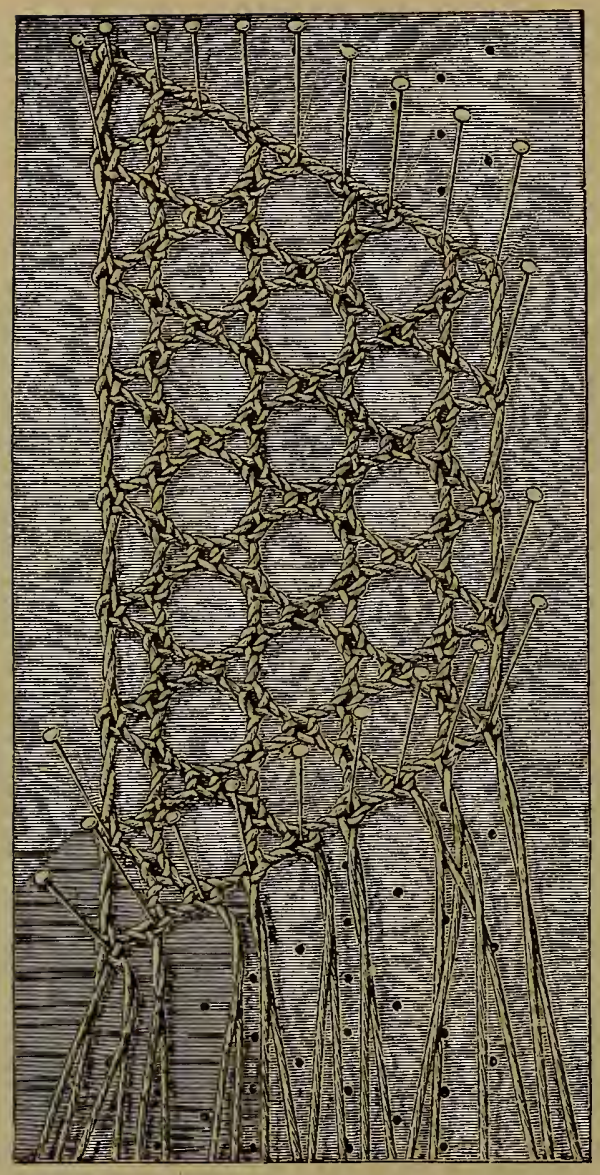

Rose Ground.

\section{Rose Ground.}

Pin 2 pairs in a, 1 in each of b, c, d, e, f, g, $\mathrm{h}$, and 2 pairs in $\mathrm{i}$. Ht $2 \mathrm{~d}$ and $3 \mathrm{~d}, \mathrm{tw}$ both pairs, pin in 1 , close with ht, and $t w$ both pairs. (A twist follows each halfthrow, so need not be again mentioned.) $\mathrm{Ht}$ 1 st and $2 d$, pin in 2, close; ht $2 \mathrm{~d}$ and $3 \mathrm{~d}$, pin in 3 , close; lit 4th and 5 th, pin in 4 , close; ht $3 \mathrm{~d}$ and 4 th, pin in 5, close ; ht $2 \mathrm{~d}$ and $3 \mathrm{~d}$, pin in 6 , close; ht 1st and $2 d$, pin in 7 , close; ht 4th and 5th, pin in 8, close; ht $2 \mathrm{~d}$ and $3 \mathrm{~d}$. pin in 9, close; ht 6th and 7 th, pin in 10 , close; and so continue. This makes a very pretty lace, and is desirable for veils and similar purposes. 


\section{Eternelle Ground.}

For 2 rows of holes, 7 pairs of bobbins are required. Pin 3 pairs in $\mathrm{a}, 1$ in $\mathrm{b}$, and 3 in $\mathrm{c}$. In wider patterns, 9 pairs are used for 3 rows, 11 for 4 rows, and so on. Wt with $2 \mathrm{~d}$ and $3 \mathrm{~d}$ pairs, 4th and 5th, and 6th and 7th; wt $3 \mathrm{~d}$ and 4 th, 4 th and 5 th, 5th and 6th, 6th and 7 th; pin in 1 , between $2 d$ and $3 d$ pairs, wt; pin in 2, between 4th and 5th pairs, wt; in 3 , between 5 th and 6 th; wt; ht 1 st and 2d, pin in 4 ; close with ht; wt $2 \mathrm{~d}$ and $3 \mathrm{~d}$, $3 \mathrm{~d}$ and 4th, 4th and 5th, 5th and 6 th, 6 th and 7 th; pin between $2 \mathrm{~d}$ and $3 \mathrm{~d}$, 4th and 5th, 6th and 7 th; then wt 6 th and 7th, 4th and 5th, 2d and $3 \mathrm{~d}$, ht 1 st and $2 \mathrm{~d}$, pin in 8, ht; wt all pairs through, and so continue.

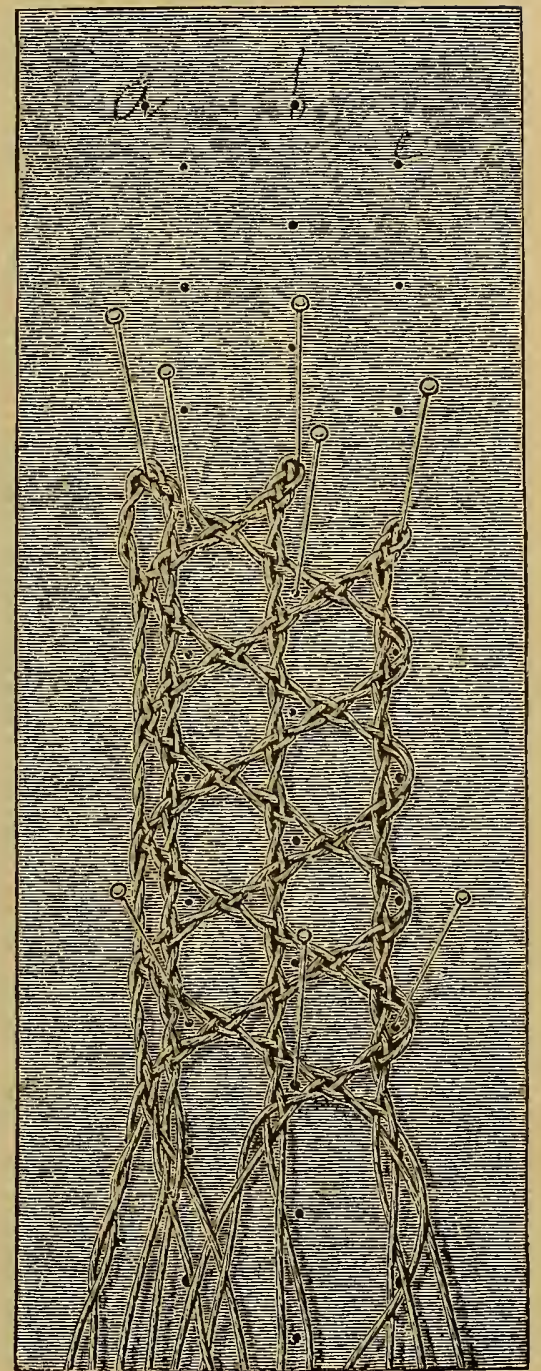

Eternelle Ground. 


\section{Braid for Battenberg or Renais= sance Work.}

The linen or cloth gronnd is nicely illustrated in this braid, which is found useful for many purposes. The pattern consists of 3 holes across the top and rertical rows at the sides, as in pattern for plain net. The illustration is enlarged, to show the work better, and the braid may be made wider

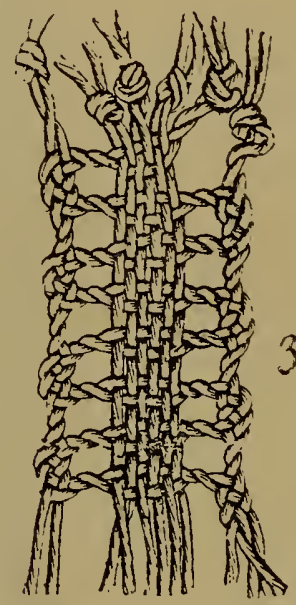

Braid for Battenberg or Renaissance Work.

or narrower, at pleasure. Use No. 50 Barbour's linen and 6 pairs of bobbins. Pin 2 pairs in 1 st hole, 3 in $2 \mathrm{~d}$, and 1 in $3 \mathrm{~d}$. Beginning at the left, *tw $2 \mathrm{~d}$ pair, ctc $2 \mathrm{~d}$ and $3 \mathrm{~d}$; ctc $3 \mathrm{~d}$ and 4 th ; ctc 4th and 5th; tw 5th and 6th, cte, pin in 1, wt; tw 5 th pair, ctc with 4 th and 5 th ; cte $3 d$ and 4 th ; ctc $2 \mathrm{~d}$ and $3 \mathrm{~d}$; tw 1 st and $2 \mathrm{~d}$, ctc, pin in 2 , wt, and repeat from $*$. 


\section{Loop Point Edging.}

Materials : Barbour's Irish flax thread, No. 100 , 8 pairs bobbins. Pin 3 pairs in a and b, 2 pairs in c. Wt $2 \mathrm{~d}$ and $3 \mathrm{~d}$, pin in 1 ; wt 1 st and $2 \mathrm{~d}, 2 \mathrm{~d}$

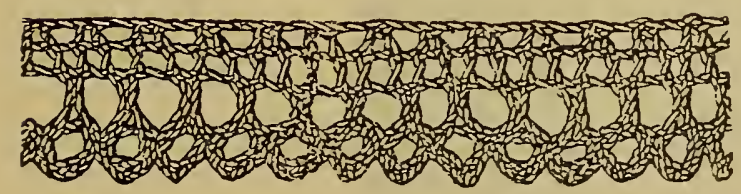

Loop Point Edging.

and $3 \mathrm{~d}$, and across to 7 th pair ; cross 6 th pair orer 7 th, 8th over 7 th, 6 th over 5 th, pin in 2 , cross 6 th over 7 th, plait 7 th and 8 th by making 4 tht, pin in 3 , plait 7 th and 8 th. wt $3 d$ and 4 th ; repeat. 


\section{Baby Lace and Insertion.}

Use Barbour's Irish flax thread, No. 120, with 6 pairs of bobbins. The pattern is similar to that for the Battenberg braid, made larger or smaller according to size of thread used. Pin 2 pairs of bobljins in each of 3 holes across the pattern. Wt $2 \mathrm{~d}$ and $3 \mathrm{~d}$ pairs, pin in 1 ; without closing, wt 1st and $2 \mathrm{~d}$, then wt $2 \mathrm{~d}$ and $3 \mathrm{~d}$, closing the pin. This makes a nice selvage for any lace. Wt $3 d$ and 4 th, 4 th and 5th, 5 th and 6 th, pin in

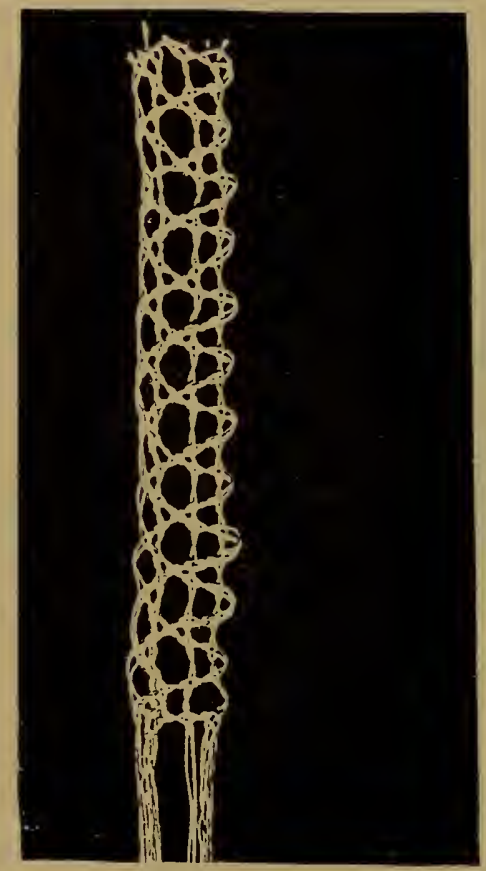

Baby Lace Insertion. 2 , close with wt; wt th and 5th. Then repeat from beginning. This may be worked very rapidly. To make the insertion to match, or if wanted alone, make both edges alike, thus: After wt 4th and 5th, working to the right, pin in 2 , do not close, wt 5th and 6 th, then wt 4 th and 5th. The insertion makes a lovely little hemstitching or bit of "drawn-work" for a handkerchief; indeed, many uses will be found for this simple lace and insertion. 


\section{Diamond Point Edging.}

Materials: Barbour's Irish flax thread, No. 50, 10 pairs of bobbins, pattern and lace-desk, with pins of large size. Pin 2 pairs of bobbins in 11, 2 in 12,1 pair each in $10,18,19$ and 20 , and 2 pairs in 21. The grounds used are plain hole and net. 'The point is made first. Beginning with 9 th and 10 th pairs, ht, pin in 1 , close. Ht to left, as directed for net ground, using 6th pair, pin in 2 , close; to right, pin in 3 , close. (I should advise making the edge with wt 9 th and 10 th, as in "Round Point Edging.") Ht to left, using 5̆th pair, pin in 4, close; to right, pin in 5 , close; to left, using 4th pair, pin in 6 , close; to right, pin in 7. close; to left, in same way, using 5tl pair, and putting pin in 8; to right, pin in 9 ; to left, using 6th pair, pin in 10 ; to right, pin in 11 ; to left, using 7 th pair, pin in 12, then, after closing, ht with 8th and 9th, and pnt aside 4 pairs, ready for use on next point. For the hole ground, ht with $3 d$ and 4th pairs, pin in 13, close; ht $2 \mathrm{~d}$ and $3 \mathrm{~d}, \mathrm{tw} 1 \mathrm{st}$ pair, wt 1 st and $2 d$, draw up threads, pin in 14 , close with wt; ht 4 th and 5 th, pin in 15 , close; ht $3 \mathrm{~d}$ and 4 th, pin in 16 , close; wt $2 \mathrm{~d}$ and $3 \mathrm{~d}, \mathrm{tw} 1 \mathrm{st}$, wt 1 st and $2 \mathrm{~d}$, pin in 17 , wt; ht 5 th and 6 th, pin in 18, close;

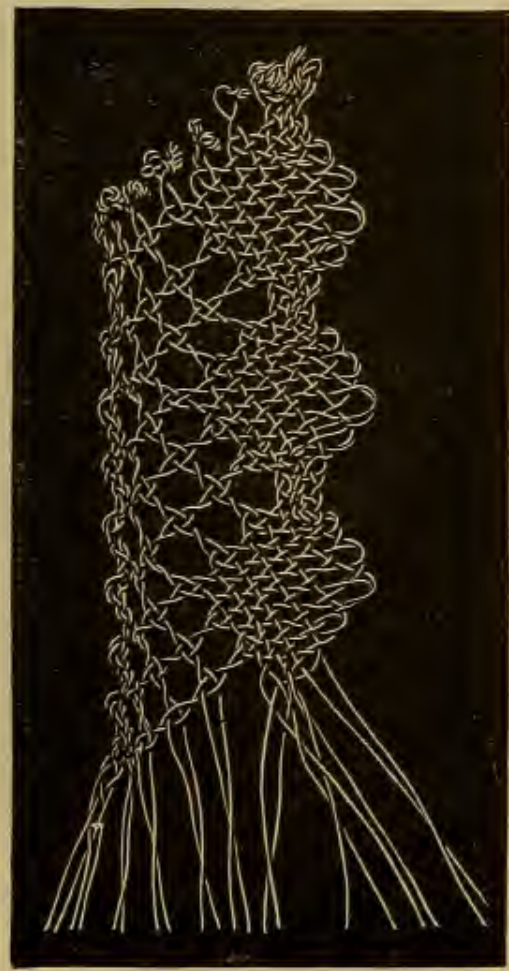

Diamond Point Edging. ht 4 th and 5 th, pin in 19 , close; ht $3 \mathrm{~d}$ and 4 th, pin in 20 , close: wt $2 \mathrm{~d}$ and $3 \mathrm{~d}, \mathrm{tw} 1$ st, wt 1 st and $2 \mathrm{~d}$, pin in 21 . wt. Repeat from beginning. This pattern mar be raried by making the upper half of the point of linen ground, and lower half of $t w i s t e d$ bars. 


\section{Antique or "Spider" Insertion.}

Materials: Barbour's Irish flax thread, No. 30 , 16 pairs of bobbins, medium pins and lace-desk.

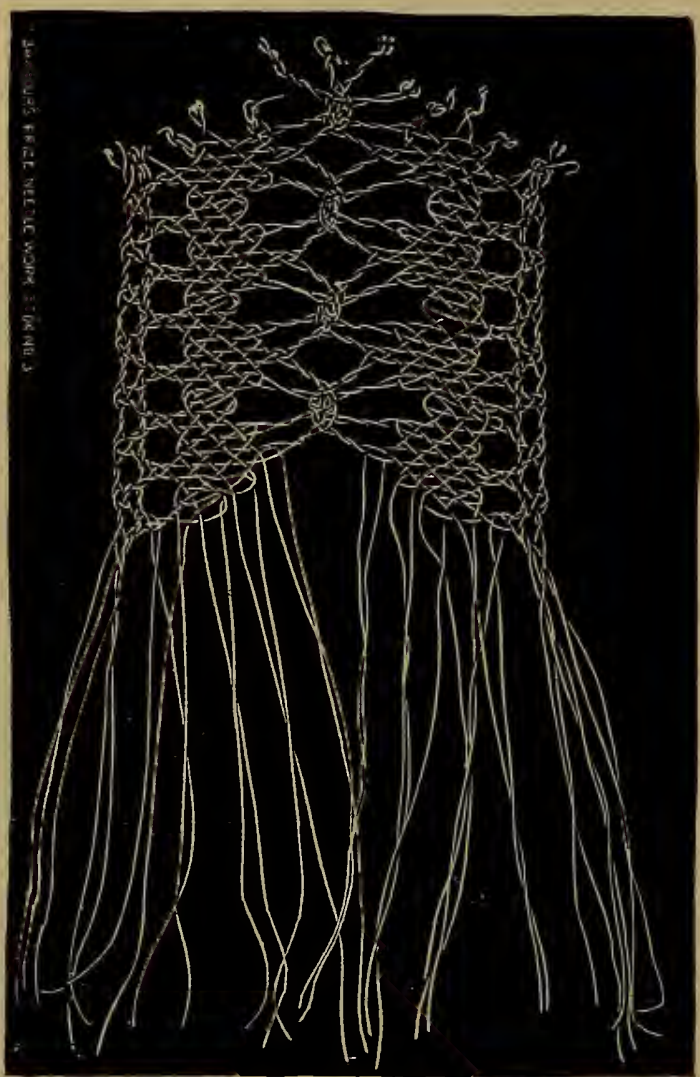

Antique or "Spider" Insertion.

Pin 3 pairs of bobbins in 11,1 pair each in 10,8 , $9,7,4,14,17,19,18,20$, and 3 in 21 .

Our illustration shows perfectly the method of 
working. Beginning with the spider, which is linen ground, tw 8th and 9 th pairs twice, ctc; tw 7 th twice, ctc with 7 th and 8th; tw 10th twice, ctc with 9 th and 10 th ; ctc with 8 th and 9 th, pin in 1 , close with ctc; ctc 9 th and 10th, 7 th and 8th, 8th and 9 th; now tw 7 th twice, ht with 6 th and 7 th, pin in 2 , $*$ close; ht 5 th and 6 th, 4 th and 5 th, pin in 3 , close; ht 5th and 6th, 6th and 7 th, tw 8 th twice, ht 7 th and 8 th, pin in 4 , close; ht 6 th and 7 th, 5 th and 6 th, 4 th and 5th, $3 \mathrm{~d}$ and 4 th, pin in 5, close; wt $2 \mathrm{~d}$ and $3 \mathrm{~d}$, tw 1 st twice, ht 1 st and $2 \mathrm{~d}$, pin in 6 , close; wt $2 \mathrm{~d}$ and $3 \mathrm{~d}$, ht 4 th and 5 th, 5th and 6 th, 6 th and 7 th, pin in 7 , close; ht 5th and 6 th, 4th and 5th, pin in 8, close; ht 5th and 6th, pin in 9, close; ht 4th and 5th, 3d and 4th, pin in 10 , close; wt $2 \mathrm{~d}$ and $3 \mathrm{~d}, \mathrm{tw}$ 1st twice, ht 1st and $2 \mathrm{~d}$, pin in 11, close; ht 4 th and 5th, 5th and 6th.* Putting these aside, work the other side of insertion in same manner, repeating from * to $*$, merely considering 16 th pair as 1 st, 15 th as 2 d, etc. Then begin at first again.

This is a desirable insertion, as it matches almost any of the "spider" or antique patterns of lace. 


\section{Round Point Edging.}

Materials : Barbour's Irish flax thread, No. 50 , 3-cord, 200-yards spools, 10 pairs of bobbins, lace-desk and pattern. Pin 2 pairs each in 17 , $14,16,11$ and 12 .

Wt with 9 th and 10 th pairs, pin in 1, close with wt. ('The wt is made with 9 th and 10th pairs throughout, in order to form a durable edge, and will not be specially referred to.) Work with ht to left, using 4th pair, pin in 2, and close (as always, unless otherwise specified) with ht; to right, pin in 3 ; to left, leaving off 4 th pair, pin in 4 ; to right, pin in 5 ; to left, leaving off 5th pair, pin in 6 ; then to right, ht with 6 th and 7 th, 7 th and 8th, 8th and 9th pairs, and put aside. Beginning with open ground, $t w 3 d$ pair, *wt with $2 \mathrm{~d}$ and $3 \mathrm{~d}$, pin in 7 , then (before closing) tw 1st pair twice, wt with 1 st and $2 d$, wt with $2 d$ and $3 d$ (thus closing in the pin), tw $2 d$ and $3 d$ pairs,* tw 4 th pair, ht with $3 d$ and 4 th, pin in 8 , close, tw $3 \mathrm{~d}$ and 4 th pairs, repeat from * to *, putting the pin in $9, \mathrm{tw}$ 5th pair, ht with 4 th and 5th, pin in 10, close, tw 4th and 5th, bt with $3 d$ and 4 th, pin in 11 , close, twist $3 \mathrm{~d}$ and 4 th, repeat from $*$ to *, putting pin in 12. To complete the net ground edge, wt with 9th and 10 th, pin in 13 , wt; work to left, using 5th pair, pin in 14, to right, pin in 15 ; to left, using 4 th pair, pin in 16 ; to right, pin in 17 ; to left, using $3 \mathrm{~d}$ pair, pin in 18 . Then ht to right, and repeat from beginning. 


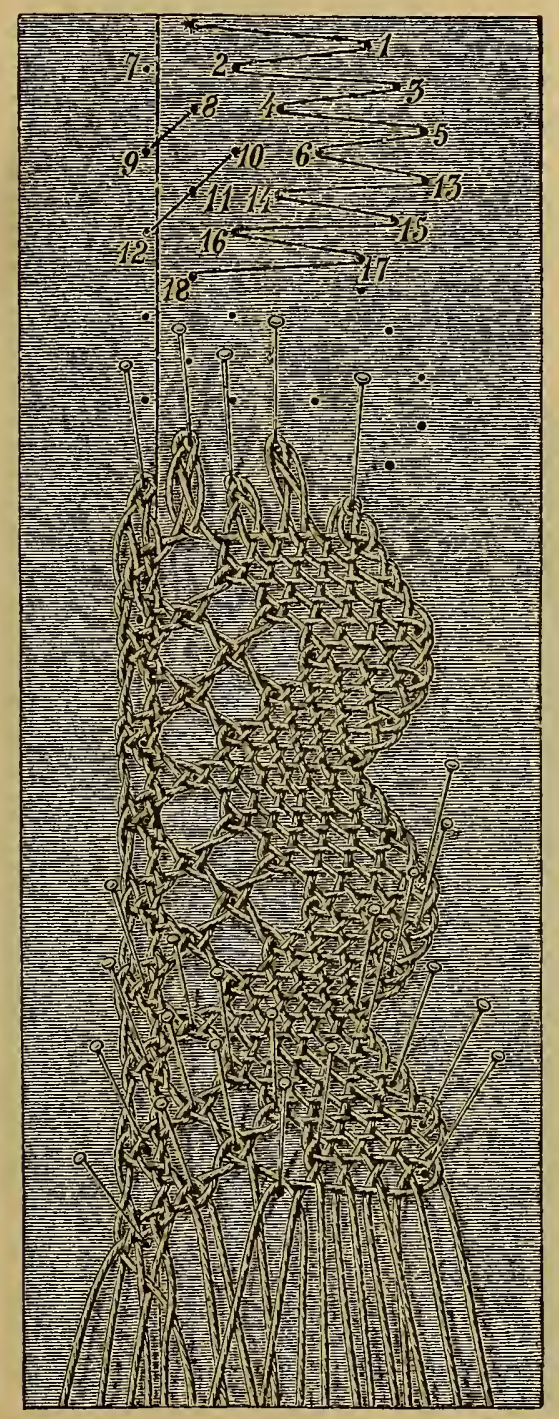

Round Point Edging. 


\section{Fairy Lace.}

Materials: Barbour's Irish flax thread, No. 250, 11 parrs bobbins, lace-desk and small pins. Pin 3 pairs in 13,1 pair in $21,23,25,27$ and 29,3 pairs in 28.

*Wt $2 d$ and $3 d$ pairs. pin in 1, wt 1st and $2 d$, wt with $2 d$ and $3 d$, closing the pin; tw $3 d$, ht with $3 d$ and 4 th, pin in 2 , ht to close, and tw both pairs.

As this is the twisted hole ground,

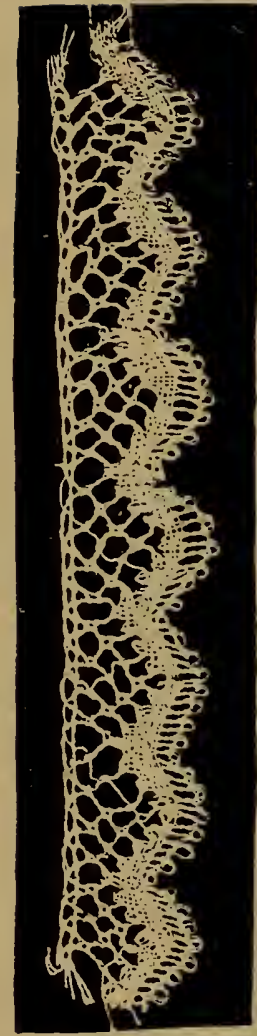

Fairy Lace. the extra twist is made after each closing ht. Ht 4 th and 5th, pin in 3 , close; lit 5th and 6 th, pin in 4 , close; ht 6th and 7 tll, pin in 5, close; now begin at $*$ and work up, not using 7 th pair ; again begin at $*$ and work $\mathrm{mp}$, leaving off 6 th pair; again, not using 5th pair. This completes the twisted hole ground. Ctc 7 th and 8th pairs, pin in 15, ctc; *ctc to right, taking in 10th pair, tw 10th twice, wt with 10th and 11th, pin in 16 , close with wt; tw 10th, * ctc to left, taking in 6th pair, pin in 17 , close with ctc, and repeat from * to $*$, putting pin in 18 ; to left, as before, taking in 5th pair, putting pin in 19 ; repeat from $*$ to *, pin in 20 ; to left, taking in 4 th pair, pin in 21 ; to right, repeating from * to $*$, pin in 22 ; to left, taking in 5th pair, pin in 23 ; to right, as before, pin in 24 ; to left, using 6 th pair, pin in 25 ; to right, pin in 26 ; to left, using 7 th pair, pin in 27 ; to right, pin in 28; to left, taking in 8th pair, pin in 29 ; to right, pin in 30 ; to left, using 8 th pair, tw 7 th, 6th, 5th and 4th twice, and begin at first again. 


\section{Copenhagen Lace.}

Materials : Barbour's Irish Hax thread, No. 50 , lace-desk, pins and 15 pairs bobbins. Pin 4 pairs in 43,1 pair at $42,41,40,39,23$ and 25,3 at 33,2 pairs at 34 .

Begin with the spider. Tw 8 th and 9 th 4 times,

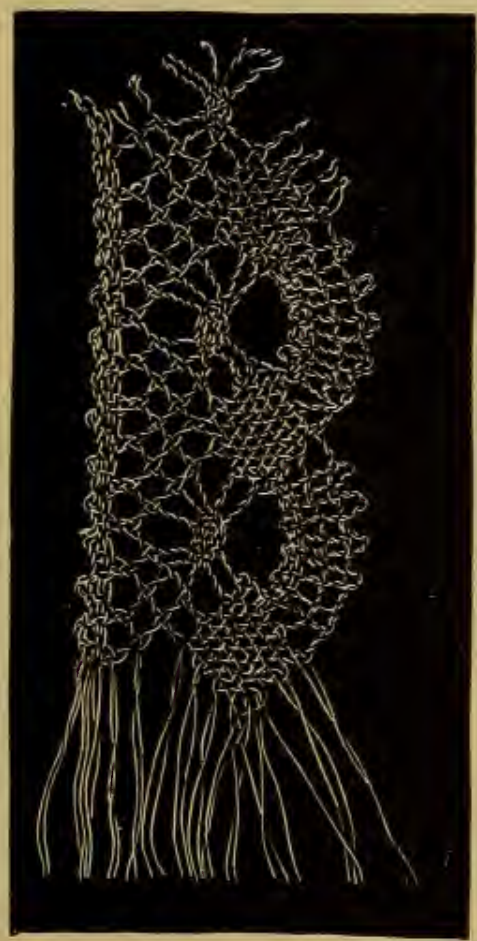

Copenhagen Lace.

ctc; tw 7 th 4 times, ctc 7 th and 8 th; tw 6 th 4 times, ctc 6 th and 7 th; tw 10 th 4 times, ctc 
9th and 10th, 8th and 9th, 7th and 8th, 6th and 7 th, pin in 1 , between 7 th and 8 th, ctc 7 th and 8 th; etc 6 th and 7 th, 8th and 9 th, 7 th and 8th, 6th and 7th; now tw each of these 5 pairs 4 times, which forms the lower "legs" of spider, or they may be twisted as used, if preferred. Ht 5th and 6th, pin in 2, close; ht 4th and 5th, pin in 3 , close ; ctc $3 \mathrm{~d}$ and 4 th, $2 \mathrm{~d}$ and $3 \mathrm{~d}$, tw 1 st twice, etc 1 st and $2 \mathrm{~d}$, pin in 4 , ctc; ctc $2 \mathrm{~d}$ and $3 \mathrm{~d}$, $3 \mathrm{~d}$ and 4 th ; ht 6 th and 7 th, pin in 5 , close; work to left, as before, repeating edge; then beginning with 7 th and 8th, ht, pin in 9, close, and work up as before, pin in 13 ; ctc with $2 \mathrm{~d}$ and $3 \mathrm{~d}, 3 \mathrm{~d}$ and 4 th; ht 10th and 11 th, pin in 14, close; lit 9th and 10 th, pin in 10, close; ht 10th and 11th, 11th and 12 th, 12 th and 13 th, pin in 16 , close; in forming the plain net diamond, work back and forth, taking on an extra pair each time until you reach pin 20 , between 14 th and 15 th pairs; then work to left, dropping off 7 th pair; then to right, leaving off 15 th, and so on, until you pin in 25 , between 10th and 11th. This completes the diamond. For the scallop, after closing with ht, ctc with 11th and 12th, 12th and 13th; tw 13th and 14th twice, ctc; same with 14 th and 15th, pin in 26 , tw each pair twice, ctc; to left, tw 13th and 14th twice, ctc; ctc 12 th and 13 th, 11 th and 12 th, pin in 27 , close with ctc; work to right as before, pin in 28 , tw and close; to left, pin in 29 ; to right, pin in 30 ; to left, pin in 31 ; to right, pin in 32 ; to left, pin in 33 ; to right, pin in 34 ; again to left, and put aside the five pairs of bobbins, having finished the scallop. Beginning with ht 6 th and 7 th, pin in 35 , close, work up and repeat edge, as already directed; begiuning with 7 th and 8th, ht, pin in 39 , and work up to edge, pin in 43 . This completes the pattern, which is a very handsome one. 
Books No. 1, No. 2, No. 3, and No. 4,

ALSO

Book of Instruction in Macrame Lace $=$ Making, and the New Illustrated Handbook of Torchon (or Bobbin) Lace $=$ Work,

will be sent to any address on receipt of ten cents each. In the Prize Needlework Series, no patterns are duplicated, and the whole form a compendium of the choicest designs.

If customers find difficulty in procuring Barbour's Irish Flax Threads and Flosses from their local stores, it will be sent from The Barbour Brothers Company, New York, post-paid, at prices below. We shall be pleased if our friends will kindly give, when writing, addresses of dealers to whom application for the threads has been made:

3-cord 200-yards spools dark blue, white, whited brown (or écru), and drabs, spool . . • . • • $\cdot$ :

3-cord carpet thread, any color, skein .

00 Ulster rope linen floss, 80 shades,

skein

10 cents. 3 cents.

5 cents.

o. 4 etching flax, any color, 80 shades, 2 skeins . . . . . . . .

Color book, containing full line of shades . . : : * * .

White Star flossette, sizes **, *****, and *****, skein . . . . . . . . .

New Irish flax lace threads, 3-cord, 200 -yards spools, No. 120 and No. 150 , spool . . . . . . .

New Honiton lace thread, 2-cord, $200-$ yards spools, No. 250 , very fine and strong, and serviceable also for the finest knitting, crocheting, and other lace-work, spool ' $\cdot$ '

Crochet thread, gray écru, and white : Nos. $16,18,20$, and 25 , ball . . . 15 cents. Nos. $30,35,40$, and 50 , ball . . . 20 cents. Nos. 60 and 70 , ball . . . . 25 cents.

Flax macramé, 4-ounce ball . . . . 25 cents.

New Ulster (or Russian) braid, per yard, 5 cents; 12 yards . . . . 50 cents.

$$
\begin{gathered}
\text { Copyright, } 1896, \\
\mathrm{BY}
\end{gathered}
$$

THE BARBOUR BRO'HERS COMPANY. 



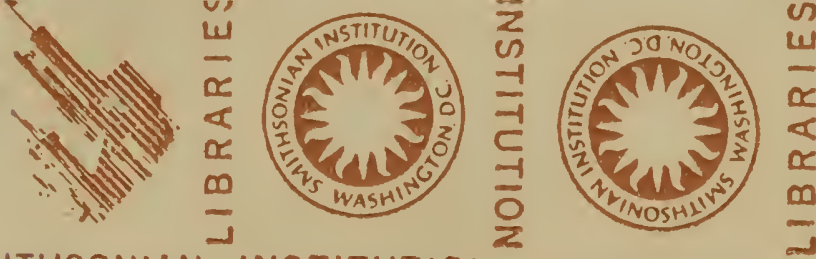

J

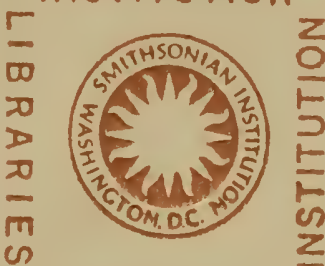

(s)
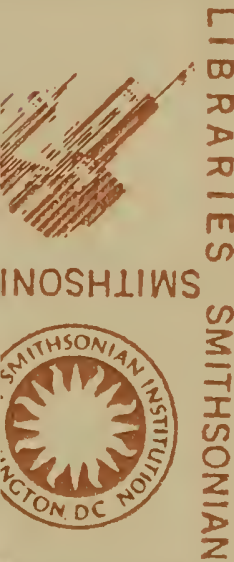

ITHSONIAN
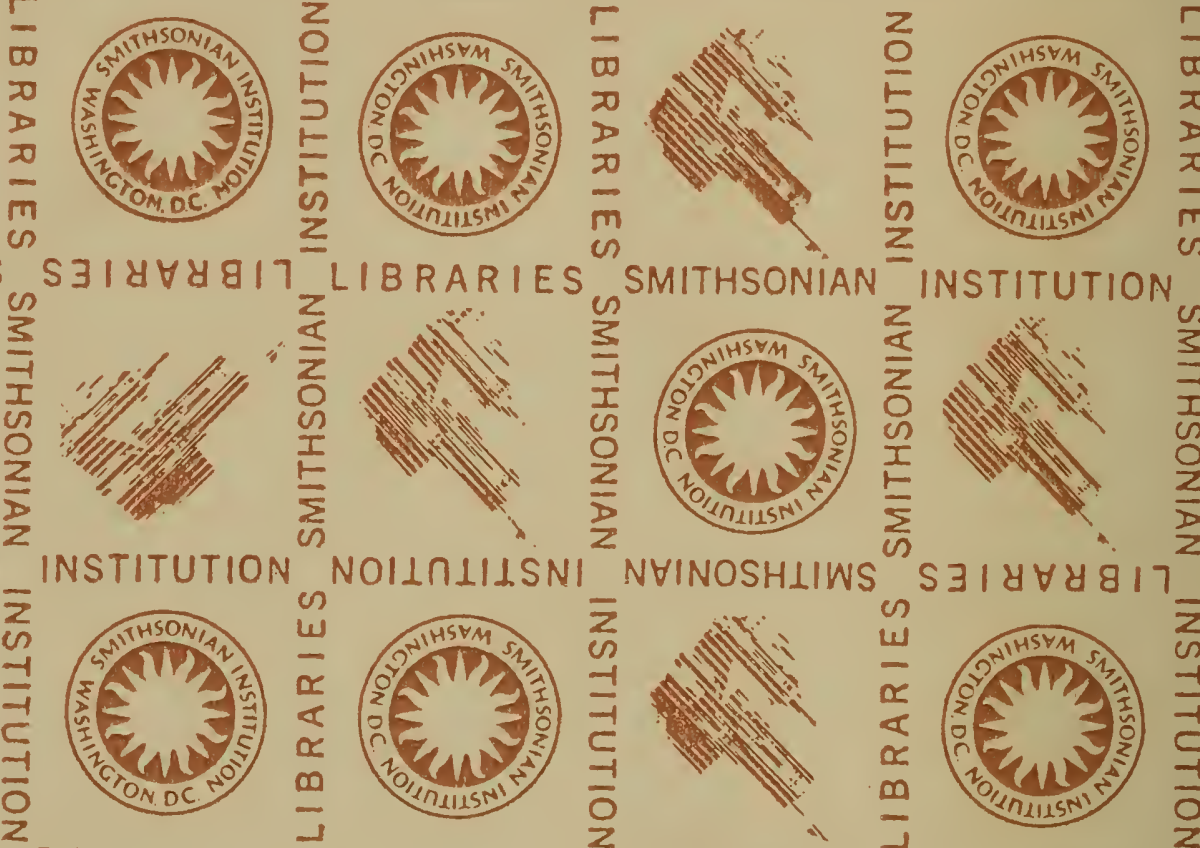

$L|B R|$
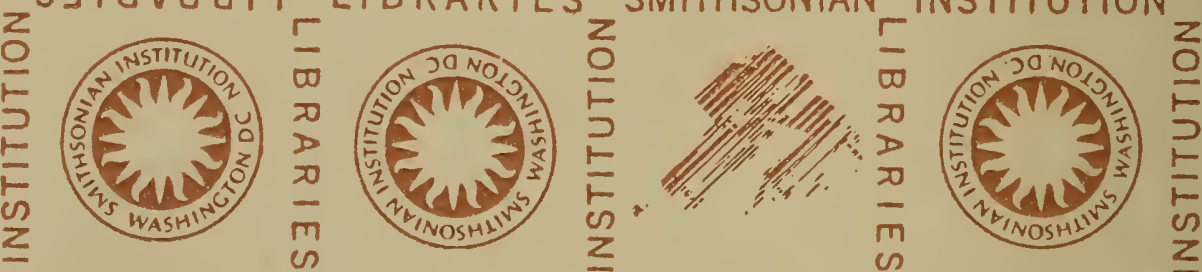

NOIIn
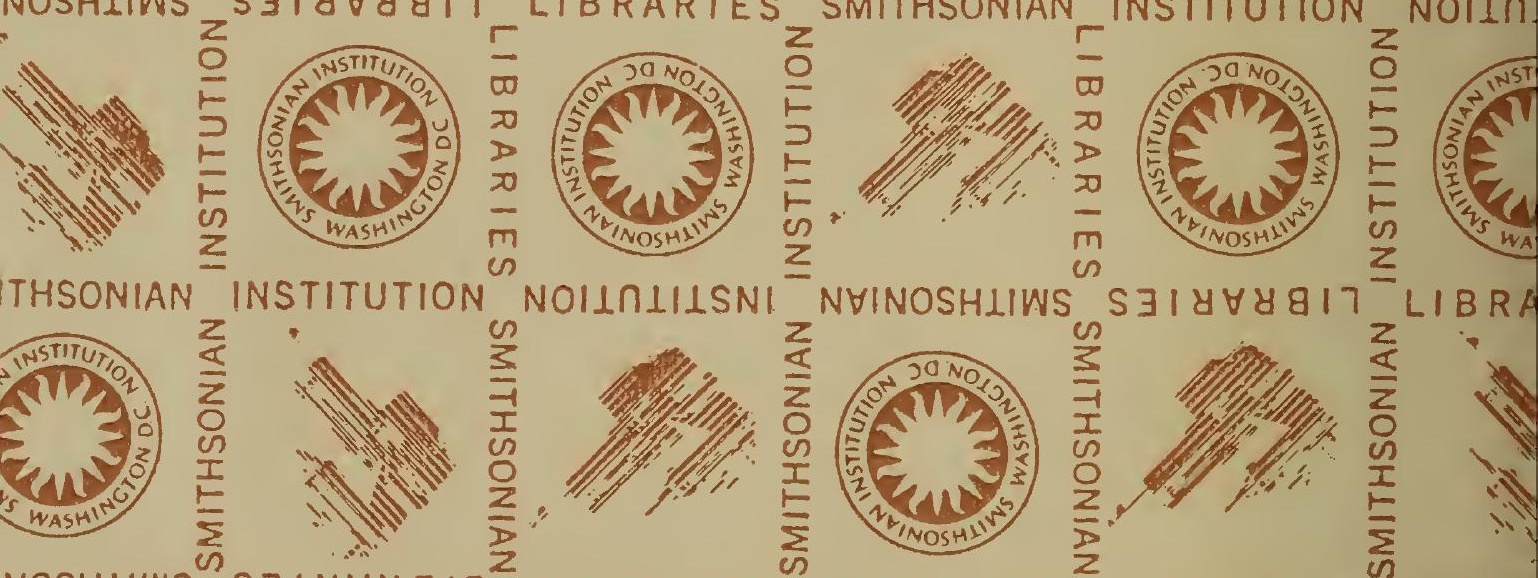

$z$
$\frac{2}{2}$
0
s
E
in
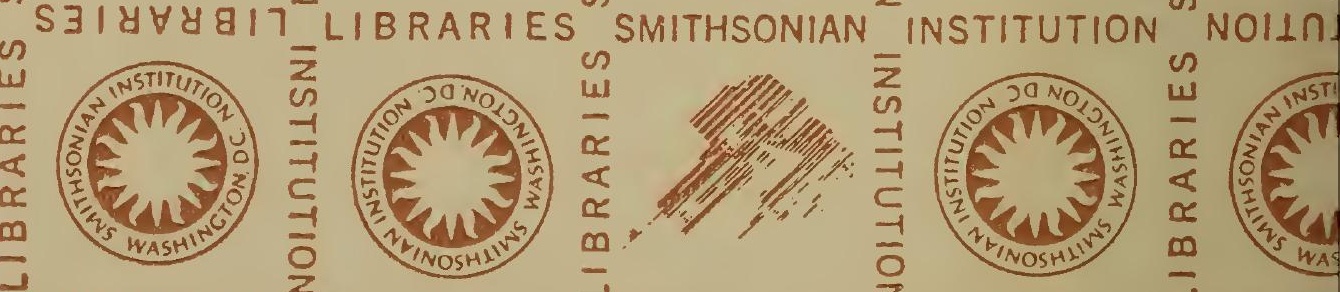

LI BRA
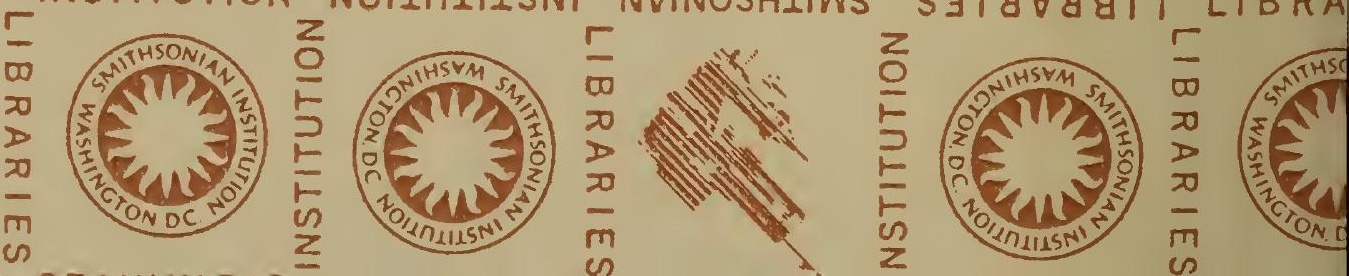
SMITHSONIAN INSTITUTION LIBRARIES 